\title{
Pregnancy rates in cattle with cryopreserved sexed spermatozoa: effects of laser intensity, staining conditions and catalase
}

\author{
JL Schenk' and GE Seidel, Jr² \\ ' XY, Inc, 2301 Research Blvd. Suite 110, Fort Collins, CO 80526-1825 USA; ${ }^{2}$ ARBL, Colorado State \\ University, Fort Collins, CO $80523-7683$ USA
}

\begin{abstract}
The overall aim of this research was to improve fertility of cattle inseminated with sexed spermatozoa by improving sperm sorting procedures. Six field trials were conducted in which 4,264 heifers were inseminated into the uterine body with cryopreserved sexed or unsexed control spermatozoa. Pregnancy or calving rates with doses of $2 \times 10^{6}$ sexed spermatozoa ranged from 32 to $51 \%$; these averaged $69 \%$ of the pregnancy rates with $20 \times 10^{6}$ unsexed, control spermatozoa (range 53 to $79 \%$ of controls). Fertility of sexed spermatozoa was especially low on farms where control fertility was low. Accuracy of sexing ranged from 86 to $91 \%$. Laser power of $150 \mathrm{~mW}$ for interrogating spermatozoa did not result in lower pregnancy rates $(43 \%)$ than when power was decreased as much as possible for a particular sorting batch (50 to 130 $\mathrm{mW}$ ) to still achieve sexing accuracy (38\% pregnant). Addition of catalase to fluids containing spermatozoa was beneficial when thawed spermatozoa were incubated in vitro for $2 \mathrm{~h}$ but had no effect on pregnancy rates. There also was no effect on pregnancy rates between two concentrations of Hoechst 33342 for staining spermatozoa. Freezing $2 \times$ $10^{6}$ sexed spermatozoa at $20 \times 10^{6} / \mathrm{ml}$ resulted in a slightly higher rate of pregnancy $(P<0.05)$ than at $10 \times 10^{6} / \mathrm{ml}$. The information obtained in these trials, along with other improvements, notably lowering pressure in the sorting system from 50 to 40 psi, has been used to improve procedures for sexing spermatozoa commercially.
\end{abstract}

\section{Introduction}

The only reliable method available for separation of spermatozoa capable of fertilization into relatively pure $\mathrm{X}$ - and $\mathrm{Y}$-chromosome-bearing populations is flow cytometry/cell sorting. The $3.8 \%$ difference in DNA content between $X$-and $Y$-chromosome-bearing bovine spermatozoa is the basis of sorting, routinely done to about $90 \%$ accuracy (Tubman et al. 2004). This technology is now commercially available via bovine genetic companies in a number of countries. However, much remains to be done to optimize the many steps that are superimposed on routine semen processing as spermatozoa are sexed. Herein are results from six field trials. from artificial insemination of heifers with sexed frozen-thawed spermatozoa that were processed by different treatments. 
Efforts described in this communication reflect modifications and improvements to those reported by Schenk et al. (1999) and Seidel et al. (1999) as the commercialization of sexed spermatozoa is a work in progress. Flow sorting of spermatozoa presents many challenges to overcome to assure that the resultant cells are capable of fertilization at rates approaching those of unsexed spermatozoa. These studies were done to determine the effect of Hoechst 33342 stain concentration, laser intensity, spermatozoa concentration during freezing and catalase on pregnancy rates in beef and dairy heifers inseminated artificially with sexed spermatozoa. A preliminary report on trials 3 and 4 was published earlier (Seidel and Schenk 2002).

\section{Hoechst 33342}

Hoechst 33342 (Bis-Benzimide, H-33342; \#H21492, Molecular Probes, Eugene, OR), a bisbenzimide vital dye that fluoresces blue when excited by the 351 and $364 \mathrm{~nm}$ lines of energy from an argon laser, can be used to distinguish $\mathrm{X}$ - and $\mathrm{Y}$-chromosome bearing populations (Johnson et al. 1987a). The dye is non-intercalating, as it binds to the minor groove of the DNA helix, with an affinity for adenine-thymine-rich regions (Muller \& Gautier 1975; Johnson et al. 1987b). However, Hoechst 33342 is suspected of inducing chromosomal damage in spermatozoa under some conditions (Munné 1994). McNutt and Johnson (1996) reported an increase in fetal mortality in rabbits during the early stages of pregnancy following insemination of flow-sorted spermatozoa. Cran et al. (1994) reported similar cleavage but reduced blastocyst development rates and reduced pregnancy rates following embryo transfer of bovine oocytes fertilized with flow-sorted spermatozoa, in comparison with unsorted, unstained spermatozoa, but many aspects of sorting spermatozoa could have been responsible. Furthermore, Parrilla et al. (2004) showed that exposure of porcine spermatozoa to Hoechst 33342 was not genotoxic when evaluating resulting offspring.

Sperm sorting is accomplished by optimizing the balance between laser power, Hoechst 33342 staining concentration, spermatozoa concentration during staining, spermatozoa concentration during sorting and sort rates. Previously, we reported staining $400 \times 10^{6}$ spermatozoa $/ \mathrm{ml}$ with $224 \mu \mathrm{M}$ Hoechst 33342 (Schenk etal. 1999). Little was known at that time regarding the use and effects of Hoechst 33342 on long-term spermatozoa viability and function. There is a threshold for uniformly staining spermatozoa with Hoechst 33342 . Furthermore, as the number of spermatozoa $/ \mathrm{ml}$ increases so does the required amount of stain. While too much stain can be toxic to spermatozoa, inadequate staining results in poor resolution of $\mathrm{X}$ - and $\mathrm{Y}$-chromosome bearing populations. As a result of concerns related to Hoechst 33342 toxicity, we now routinely lower the spermatozoa concentration for staining from the previously reported $400 \times 10^{6}$ spermatozoa $/ \mathrm{ml}$ to 100 to $200 \times 10^{6}$ spermatozoa $/ \mathrm{ml}$, which enables lowering the Hoechst 33342 stain concentration accordingly.

\section{Laser intensity}

Hoechst 33342 usually is excited with 351 to $364 \mathrm{~nm}$ lines of light, wavelengths that appear not to be absorbed by nucleic acids or proteins. However, Libbus et al. (1987) reported that staining with Hoechst 33342 and irradiating spermatozoa during flow sorting could increase the incidence of chromosome aberrations. Meanwhile, Teng et al. (1988) suggested that Hoechst 33342 bound to DNA provided protection against radiation damage, at least for some somatic cells. Garner et al. (2001a) studied different aspects of flow-sorting bovine spermatozoa. DNA integrity of spermatozoa expressed as COMPot (\% cells outside of the main population) (Darzynkiewicz et al. 1975) was studied by the sperm chromatin structure assay (SCSA) (Ballachey 
etal. 1987) for spermatozoa samples processed as: (1) unsorted controls; (2) sorted spermatozoa with no stain and no laser illumination; (3) sorted spermatozoa with laser illumination (150 $\mathrm{mW}$ ) but no stain; (4) sorted spermatozoa with stain but no illumination; or (5) sorted spermatozoa with both stain and laser excitation. They found that staining and exposure of spermatozoa to wavelengths of light used for sexing had little effect on the integrity of spermatozoa DNA. Furthermore, they concluded that the mechanical stresses of sorting and/or post-sorting centrifugation appeared to increase the proportion of spermatozoa with damaged DNA, but that neither Hoechst 33342 staining nor exposure to laser illumination during sorting increased the potential damage as determined by COMP $\alpha$ t.

\section{Catalase}

Shannon and Curson (1972) reported that addition of catalase eliminated peroxide, a byproduct produced by dead spermatozoa. They found that catalase increased viability of spermatozoa stored $44 \mathrm{~h}$ at $37^{\circ} \mathrm{C}$ and eliminated toxicity of dead spermatozoa. Klinc et al. (2005) used an extender containing catalase for sexed bovine spermatozoa that resulted in excellent pregnancy rates. To test potential benefits for sorting spermatozoa, laboratory experiments were conducted to determine the optimal concentration of catalase in different sorting media.

\section{Materials and methods}

\section{Semen collection}

Semen for all trials was collected from bulls on a routine collection schedule using an artificial vagina (Schenk 1998). Ejaculates had to contain $>50 \%$ progressively motile and $>75 \%$ morphologically normal spermatozoa for use in experiments. Antibiotics were added to the raw ejaculate as described by Shin (1986) within $15 \mathrm{~min}$ of collection, and the concentration of spermatozoa was determined using a spectrophotometer.

Procedures for evaluation of spermatozoa in vitro in the presence or absence of catalase

Catalase (\#C40, Sigma Chemical Co., St. Louis, MO) was added to each of the media to give final concentrations of $0,0.2$ or $2 \mu \mathrm{g} / \mathrm{ml}$ after spermatozoa staining, collection and processing and therefore was added to 4\% egg yolk-TALP (after spermatozoa were stained), $20 \%$ egg yolk catch buffer (during sorting) and $20 \%$ egg yolk Tris-AB extender (prior to cryopreservation). Neat ejaculates from each of 6 bulls were incubated at room temperature $\left(22^{\circ} \mathrm{C}\right)$ for 1 and $5 \mathrm{~h}$ prior to staining and sorting to simulate the amount of oxidation that occurs in the neat ejaculate throughout the sorting day. Spermatozoa were "bulk sorted" (Schenk et al. 1999) and frozen in $0.25 \mathrm{ml}$ straws at $10 \times 10^{6}$ total spermatozoa $/ \mathrm{ml}\left(2 \times 10^{6} \mathrm{spermatozoa} /\right.$ dose $)$. Straws were thawed for $30 \mathrm{sec}$ at $37.5^{\circ} \mathrm{C}$ for evaluation. Quality of spermatozoa was assessed using visual estimates of progressive motility ( 2 observers, blind to treatments) after 30 and $120 \mathrm{~min}$ of incubation at $37.5^{\circ} \mathrm{C}$.

Procedures for sexing, processing and insemination of spermatozoa

Sexing of spermatozoa at 85 to $90 \%$ accuracy was accomplished with a MoFlo ${ }^{(B)}$ SX sperm sorter (Dako, Fort Collins, CO), operated at: 50 psi (Seidel \& Garner 2002); 20,000 events per sec; and sort rates of 2,500 to 4,000 spermatozoa per sec. The sheath fluid composition was as 
described by Schenk et al. (1999). Spermatozoa for all field trials were stained for $45 \mathrm{~min}$ at $34.5^{\circ} \mathrm{C}$ at $200 \times 10^{6}$ spermatozoa/ml, unless indicated otherwise, in a modified TALP buffer (Schenk et al. 1999) that was adjusted to $\mathrm{pH} \mathrm{7.4.} \mathrm{After} \mathrm{staining,} \mathrm{spermatozoa} \mathrm{were} \mathrm{diluted} \mathrm{to}$ half the staining concentration with an equal volume of TALP with $4 \%$ egg yolk, adjusted to $\mathrm{pH}$ 5.5 after which $0.002 \%$ food coloring dye (FD\&C \#40: Johnson \& Welch 1999) was added. The final $\mathrm{pH}$ of the stained spermatozoa sample was $\sim 6.8$ to 7.0 .

Just prior to flow sorting, samples were filtered at unit gravity through a $50 \mu \mathrm{m}$ CellTrics $^{\text {(i) }}$ disposable filter (\#04-0042-2317, Partec GmbH, Münster, Germany). Spermatozoa were stained with $112.5 \mu \mathrm{M}$ Hoechst 33342 and interrogated with $150 \mathrm{~mW}$ of laser intensity except where Hoechst 33342 staining concentration and laser intensity were used as treatments. Sexed spermatozoa were frozen in $0.25-\mathrm{ml}$ polyvinylchloride straws in a $20 \%$ egg yolk-Tris extender (6\% glycerol) as described previously (Schenk et al. 1999). Except as described for Trial 4 , sexed spermatozoa were frozen at $20 \times 10^{5} / \mathrm{ml}$, so for $2 \times 10^{6}$ total spermatozoa, only $100 \mu$ of the $0.25-\mathrm{ml}$ straw were filled. This was accomplished by centering the $100 \mu \mathrm{l}$ column inside the straw with air pockets to either sides of the sperm column and Tris A-B extender without spermatozoa to assure a proper seal on each end of the straw. Inseminates contained at least $30 \%$ progressively motile spermatozoa after thawing for $30 \mathrm{sec}$ in $37.5^{\circ} \mathrm{C}$ water. The occasional batches of sorted spermatozoa that did not meet this standard were discarded. For all trials, the dose of sexed spermatozoa was $2 \times 10^{6}$ total spermatozoa inseminated conventionally into the uterine body. Data from 5 field trials (Seidel \& Schenk, unpublished) in addition to previous research (Seidel et al, 1999) showed no consistent improvement in pregnancy rates above $2 \times 10^{6}$ frozen sexed spermatozoa per dose when inseminating heifers into the uterine body 12 to $24 \mathrm{~h}$ after observed standing estrus.

Each study had an unsexed control of $20 \times 10^{6}$ spermatozoa/dose to determine the intrinsic fertility of the cattle using standard procedures. All cattle were in commercial herds in agricultural settings. University personnel conducted the estrus detection, semen handling, insemination, and pregnancy diagnoses for Trials 1 and 2. Similar personnel were on site for Trial 6 to assist with semen thawing and handling, estrus detection, and record keeping. For Trials 3 to 5 ; farm personnel carried out all of these procedures.

\section{Statistical procedures}

Statistical treatment of data for all trials was by analysis of variance with a fixed effect model including treatments, bulls, and herds where appropriate plus first order interactions. Since subclass means were almost always in the range of 20 to $80 \%$ pregnant, data were not transformed for analysis. Numbers of animals pregnant are presented, as well as least squares means of the percentage of females pregnant. Meta-analyses were done by single degree of freedom $\chi^{2}$ with the Fisher-Yates correction.

\section{Procedures for Trial 1 - Angus heifers in Colorado}

The experimental objective was to compare pregnancy rates in Angus heifers following insemination of $2 \times 10^{5}$ total sexed frozen/thawed spermatozoa isolated by flow sorting methods with different laser intensities. The high laser intensity was fixed at $150 \mathrm{~mW}$. The low laser intensity varied by sorting day, bull and ejaculates within bulls and was defined as the lowest laser intensity that would result in sufficient resolution between $\mathrm{X}$-and $\mathrm{Y}$-chromosome bearing spermatozoa to assure a $\sim 85+\%$ purity; range $=55$ to $130 \mathrm{~mW}$ (median power $=99 \mathrm{~mW}$ ). 
Both $\mathrm{X}$ - and $\mathrm{Y}$-chromosome-bearing spermatozoa were sorted and processed. Sorted spermatozoa $\left(2 \times 10^{6}\right)$ were packaged at $20 \times 10^{6} \mathrm{spermatozoa} / \mathrm{ml}$ into $0.25 \mathrm{ml}$ straws as $100 \mu \mathrm{l}$ columns. An unsorted control treatment containing $20 \times 10^{6}$ total spermatozoa was included in this and subsequent field trials.

Estrus of Angus heifers ( $N=412$ ) was synchronized by feeding $500 \mathrm{mg}$ melengesterol acetate with pelleted grain for $12 \mathrm{~d}$ followed by i.m. injection of $25 \mathrm{mg}$ prostaglandin $\mathrm{F}_{2} \alpha 18 \mathrm{~d}$ later $\left(\mathrm{MGA}-\mathrm{PGF}_{2} \alpha\right)$. Heifers were inseminated with spermatozoa from one of three Angus bulls 12 to $24 \mathrm{~h}$ after visually observed standing estrus. All inseminates were deposited into the uterine body. Two-thirds of the heifers received sexed spermatozoa; heifers were randomly allocated to semen treatement from one of the three bulls and one of the three inseminators. Pregnancy was diagnosed with ultrasound $\sim 60 \mathrm{~d}$ after insemination.

\section{Procedures for Trial 2 - Angus heifers in Colorado}

Laser intensity was again studied, using spermatozoa from the same treatments and only two of the bulls in Field Trial 1. Angus heifers $(N=169)$ were inseminated with $2 \times 10^{6}$ total $X$-or Y-chromosome-bearing sexed spermatozoa. Control inseminates contained $20 \times 10^{6}$ total unsexed spermatozoa. Heifers were synchronized for estrus using variations on the MGA-PGF $\alpha$ system and were mass-mated 70-74 h after the prostaglandin injection (no visual estrus detection). Pregnancy was diagnosed with ultrasound $\sim 60 \mathrm{~d}$ after insemination.

\section{Procedures for Trial 3 - Angus heifers in South Dakota}

The experimental objective was to compare pregnancy rates for spermatozoa sorted with different laser intensities and unsexed control spermatozoa. Once again, the high laser intensity was fixed at $150 \mathrm{~mW}$ and the low laser intensity was reduced to 50 to $90 \mathrm{~mW}$ (median power $=65$ $\mathrm{mW}$ ). Sexed inseminates were cryopreserved in $0.25 \mathrm{ml}$ straws at $20 \times 10^{6}$ spermatozoa $/ \mathrm{ml}$ as $100 \mu \mathrm{l}$ columns containing $2 \times 10^{6}$ total spermatozoa. Unsexed controls contained $20 \times 10^{6}$ total spermatozoa/dose. An additional control containing $30 \times 10^{6}$ total spermatozoa/dose was processed and frozen by a North American bull genetic center. Spermatozoa from a single Angus bull were used to inseminate 195 Angus heifers synchronized with the MGA-PGF $\alpha$. protocol. Heifers were inseminated $12 \mathrm{~h}$ after observed standing estrus by one of two inseminators. Pregnancy was determined using ultrasonography at $\sim 60 \mathrm{~d}$ after artificial insemination.

\section{Procedures for Trial 4 - Holstein heifers in Wisconsin}

The effects of stain concentration, laser intensity and spermatozoa concentration for freezing of sex-sorted, frozen-thawed spermatozoa on pregnancy rates were determined. Sexed inseminates containing $2 \times 10^{6}$ total spermatozoa were cryopreserved in $0.25 \mathrm{ml}$ straws at either $10 \mathrm{x}$ $10^{6} \mathrm{spermatozoa} / \mathrm{ml}$ (full straws) or $20 \times 10^{6} \mathrm{spermatozoa} / \mathrm{ml}(100 \mu /$ columns). Unsexed control inseminates contained $20 \times 10^{6}$ total spermatozoa. Spermatozoa for sorting were stained with $112.5 \mu \mathrm{M}$ Hoechst 33342 (high stain) at $200 \times 10^{6}$ spermatozoa $/ \mathrm{ml}$ or $55.8 \mu \mathrm{M}$ Hoechst 33342 (low stain) at $100 \times 10^{6} \mathrm{spermatozoa} / \mathrm{ml}$. The high laser intensity used to excite the dye was fixed at $150 \mathrm{~mW}$. For the low intensity treatment, laser power was reduced as much as possible (50 to $130 \mathrm{~mW}$ ) as described for Trial 1. These methodologies were combined into the following four treatments for sexed spermatozoa at $2 \times 10^{6}$ spermatozoa per dose: (1) $10 \times 10^{6}$ spermatozoa/ml, high laser, high stain; (2) $20 \times 10^{6}$ spermatozoa/ml, high laser, high stain; (3) 
$20 \times 10^{5}$ spermatozoa $/ \mathrm{ml}$, low laser, high stain; and (4) $20 \times 10^{6}$ spermatozoa $/ \mathrm{ml}$, low laser, low stain. Semen was collected and prepared from one of three Holstein bulls and used to treat approximately equal numbers of Holstein heifers. Holstein heifers $(\mathrm{N}=816)$ from 19 herds were inseminated with spermatozoa from one of the treatments or control. Herds in which fewer than 20 heifers were inseminated ( 9 herds, 101 inseminations) were not included in the statistical analyses; herd effects were included in the statistical model. Fetal sex was diagnosed in some of the herds by ultrasound at 8 to 10 weeks of gestation.

\section{Procedures for Trial 5 - Holstein heifers in five states}

The objective of this field trial was to determine pregnancy rates in Holstein heifers inseminated with sexed spermatozoa stained with either $63.0 \mu \mathrm{M}$ or $112.5 \mu \mathrm{M}$ Hoechst stain and treated with or without $0.5 \mu \mathrm{g} / \mathrm{ml}$ catalase. Additionally, these treatments were further studied as sorted spermatozoa frozen either 8 or $13 \mathrm{~h}$ post-collection. We also included a Non-Sort Control (NSC) inseminate containing $2 \times 10^{6}$ total spermatozoa treated with $0.5 \mu \mathrm{g} / \mathrm{ml}$ catalase that were stained with $112,5 \mu \mathrm{M}$ Hoechst, diluted with sheath fluid $(800,000$ spermatozoa/ml) and processed as sorted spermatozoa, but without sorting. Unsexed control inseminates were not treated with catalase and contained $20 \times 10^{6}$ total spermatozoa per dose. All control spermatozoa were frozen $8 \mathrm{~h}$ post-collection. This field trial included 3 Holstein bulls and 10 dairy herds located in California, Nebraska, New York, Utah and Wisconsin.

\section{Procedures for Trial 6 - Crossbred heifers in Wyoming}

To test the effects of catalase further, we conducted a field trial to determine calving rates following insemination of spermatozoa that were processed with or without $0.5 \mu \mathrm{g} / \mathrm{ml}$ catalase. Further, we had been filling straws of sexed spermatozoa as columns at $20 \times 10^{6}$ spermatozoa/ $\mathrm{ml}$. However, automated straw filling would be a requirement to commercialize procedures. Therefore, we also compared calving rates after insemination of $2 \times 10^{6}$ sexed spermatozoa frozen at $10 \times 10^{6}$ spermatozoa $/ \mathrm{ml}$ in automatically filled straws and $20 \times 10^{6} \mathrm{spermatozoa} / \mathrm{ml}$ in manually filled straws.

Finally, we wanted to know if $2 \times 10^{6}$ total spermatozoa were sufficient to maintain calving rates at commercially acceptable levels. Therefore, we included a high dose unsexed control $\left(20 \times 10^{6}\right.$ total spermatozoa) and a low dose unsexed control $\left(2 \times 10^{6}\right.$ total spermatozoa). Unsexed control spermatozoa were not treated with catalase; half of the inseminates with sexed spermatozoa were supplemented with catalase.

Non-estrus synchronized crossbred Salers heifers $(N=1,262)$ were inseminated by a single inseminator $\sim 12 \mathrm{~h}$ after first visually detected estrus with spermatozoa from one of two Red Angus bulls. Two-thirds of the heifers received sexed inseminates, while $\sim 16 \%$ of heifers received semen from the high dose control and $\sim 16 \%$ of heifers were inseminated with the low dose control.

\section{Results}

Laboratory catalase experiment

There were large bull differences $(\mathrm{P}<0.0002)$ throughout this experiment. Post-thaw progressive spermatozoa motility averaged over all other treatments did not differ due to ejaculate age at $1 \mathrm{~h}(30 \mathrm{~min}$ incubation $=47 \%, 120 \mathrm{~min}$ incubation $=40 \%)$ compared to $5 \mathrm{~h}(30 \mathrm{~min}$ 
incubation $=45 \%, 120$ min incubation $=38 \%$ ). Catalase had no effect on post-thaw spermatozoa motility after $30 \mathrm{~min}$ post-thaw incubation. Catalase at both concentrations resulted in significantly higher $(P<0.001)$ spermatozoa motility $(0.2 \mu \mathrm{g} / \mathrm{ml}=42 \%$ and $2.0 \mu \mathrm{g} / \mathrm{ml}=41 \%$ ) than for controls $(34 \%)$ at 120 min of incubation post-thaw. The results of this in vitro experiment suggest that catalase only had a beneficial anti-oxidant effect during post-thaw spermatozoa incubation.

\section{Trial 1 - Angus heifers in Colorado}

Pregnancy rates were similar for X-and $Y$-chromosome bearing inseminates, 52 and $45 \%$ respectively $(\mathrm{P}>0.2)$; pooled data are presented in Table 1. Furthermore, pregnancy rates for controls and the high laser treatment were not significantly different $(P>0.1)$ but were lower $(\mathrm{P}<0.05)$ for spermatozoa interrogated with low laser intensity $(43 \%)$ (Table 1$)$. There were no effects of bulls or inseminators $(P>0.1)$.

Table 1. Results of Trial 1. Effects of laser power during interrogation of spermatozoa for determining DNA content on pregnancy rates.

\begin{tabular}{lccc}
\hline Treatment & $\mathrm{N}$ & $\begin{array}{c}\text { Number } \\
\text { pregnant }\end{array}$ & $\begin{array}{c}\text { Least squares } \\
\text { means }(\%)\end{array}$ \\
\hline $20 \times 10^{6}$ unsexed (control) & 129 & 83 & $65^{\circ}$ \\
$2.0 \times 10^{6}$ sexed - high laser & 143 & 79 & $55^{\circ}$ \\
$2.0 \times 10^{6}$ sexed - low laser & 140 & 60 & $43^{\mathrm{b}}$ \\
\hline
\end{tabular}

${ }^{a b}$ Least squares means without common superscripts differ $(P<0.05)$.

Trial 2 - Angus heifers in Colorado

Unlike the results found in Field Trial 1, laser intensity did not affect pregnancy rates for sexed spermatozoa. However, pregnancy rates were higher $(\mathrm{P}<0,05)$ for unsexed controls compared to sexed spermatozoa (Table 2 ). There were no significant bull effects $(P>0.1)$.

Table 2. Results of Trial 2. Effects of laser power during interrogation of spermatozoa for determining DNA content on pregnancy rates.

\begin{tabular}{lccc}
\hline Treatment & $\mathrm{N}$ & $\begin{array}{c}\text { Number } \\
\text { pregnant }\end{array}$ & $\begin{array}{c}\text { Least squares } \\
\text { means }(\%)\end{array}$ \\
\hline $20 \times 10^{6}$ unsexed (control) & 59 & 38 & $65^{\mathrm{a}}$ \\
$2.0 \times 10^{6}$ sexed - high laser & 49 & 21 & $48^{\mathrm{b}}$ \\
$2.0 \times 10^{6}$ sexed - low laser & 61 & 29 & $46^{\mathrm{b}}$
\end{tabular}

n,beast squares means without common superscripts differ $(\mathrm{P}<0.05)$.

\section{Trial 3 - Angus heifers in South Dakota}

In this field trial, we again found no effect of laser intensity on pregnancy rates (Table 3). Fertility of sexed spermatozoa was not significantly lower than unsexed spermatozoa but the numbers of observations per treatment were low. Unsexed control pregnancy rates were nearly identical after insemination with spermatozoa from the two treatments. Pregnancy rates for sexed inseminates were $78 \%$ of controls. There were no effects due to the inseminators $(P>0.05)$. Sexed inseminates resulted in $91 \%$ female fetuses compared to $42 \%$ female fetuses for controls. 
Table 3. Results of Trial 3. Effects of laser power during interrogation of spermatozoa for DNA content on pregnancy rates.

\begin{tabular}{lccc}
\hline Treatment & N & $\begin{array}{c}\text { Number } \\
\text { pregnant }\end{array}$ & $\begin{array}{c}\text { Least squares } \\
\text { means }(\%)\end{array}$ \\
\hline Genetic center control, $30 \times 10^{6}$ unsexed & 50 & 22 & 50 \\
Same ejaculate control, $20 \times 10^{6}$ unsexed & 49 & 21 & 48 \\
$2.0 \times 10^{6}$ sexed - high laser & 50 & 18 & 38 \\
$2.0 \times 10^{6}$ sexed - low laser & 46 & 17 & 38 \\
\hline
\end{tabular}

No significant differences $(P>0.1)$.

Control: $18 / 43$ ( $42 \%$ female fetuses).

Sexed spermatozoa: $32 / 35(91 \%)$ female fetuses.

\section{Trial 4 - Holstein heifers in Wisconsin}

In this trial, all treatments with sexed spermatozoa ( $2 \times 10^{6}$ spermatozoa per inseminate) resulted in lower pregnancy rates than for unsexed control spermatozoa $\left(20 \times 10^{6}\right.$ spermatozoa per inseminate) (Table 4). There also appeared to be a higher pregnancy rate when freezing sexed spermatozoa at $20 \times 10^{6} / \mathrm{ml}$ (half the volume) compared to $10 \times 10^{6} / \mathrm{ml}(\mathrm{P}<0.054$; the second and third treatments listed in Table 4). However, there was no effect of laser intensity (third versus fourth treatments listed in Table 4) nor of Hoechst 33342 stain concentration (fourth versus fifth treatments listed in Table 4).

Table 4. Results of Trial 4. Effects of Hoechst 33342 stain concentration and laser power during interrogation of spermatozoa for DNA content and of spermatozoa concentration during cryopreservation on pregnancy rates.

\begin{tabular}{|c|c|c|c|}
\hline Treatment & $N$ & $\begin{array}{l}\text { Number } \\
\text { pregnant }\end{array}$ & $\begin{array}{c}\text { Least squares } \\
\text { means }(\%)\end{array}$ \\
\hline $20 \times 10^{6}$ unsexed spermatozoa $\left(87 \times 10^{6} / \mathrm{ml}\right)$ & 143 & 83 & $59^{c}$ \\
\hline $\begin{array}{l}2.0 \times 10^{6} \text { sexed spermatozoa - high } \text { laser }^{4} \text {, } \\
\text { high } \operatorname{stain}^{6}\left(10 \times 10^{6} / \mathrm{ml}\right)\end{array}$ & 177 & 43 & $28^{d}$ \\
\hline $\begin{array}{l}2.0 \times 10^{6} \text { sexed spermatozoa - high laser, } \\
\text { high stain }\left(20 \times 10^{6} / \mathrm{ml}\right)\end{array}$ & 192 & 67 & $38^{e}$ \\
\hline $\begin{array}{l}2.0 \times 10^{6} \text { sexed spermatozoa - low laser, } \\
\text { high stain }\left(20 \times 10^{6} / \mathrm{ml}\right)\end{array}$ & 153 & 44 & $30^{d e}$ \\
\hline $\begin{array}{l}2.0 \times 10^{6} \text { sexed spermatozoa - low laser, } \\
\text { low stain }\left(20 \times 10^{6} / \mathrm{ml}\right)\end{array}$ & 151 & 42 & 30 de \\
\hline
\end{tabular}

High laser $=150 \mathrm{~mW}$; low laser ranged from $50-130 \mathrm{~mW}$.

bow stain was $55.8 \mu \mathrm{M}$ Hoechst 33342 ; high stain was $112.5 \mu \mathrm{M}$ Hoechst 33342.

c.d,eLeast squares means without common superscripts differ $(P<0.05)$.

There were large herd-to-herd differences in fertility $(\mathrm{P}<0.01)$. A more in-depth analysis divided herds into low, medium, and high fertility groups based on least-squares means. Pregnancy rates of sexed spermatozoa (all treatments) as a percent of control, unsexed spermatozoa were 60,64 and $36 \%$ for high, medium, and low fertility herds, respectively. Thus, fertility of sexed spermatozoa was particularly low in low fertility herds, which also tended to be larger herds. There were no significant bull effects $(P>0.1)$. The sex ratio of the 137 fetuses examined resulting from sexed spermatozoa was $86 \%$ females; the sex ratio of 60 control fetuses was $52 \%$ females. 
Trial 5 - Holstein heifers in five states

Pregnancy rates (Table 5) with sexed spermatozoa were lower $(P<0.05)$ than those for unsexed control inseminates. There was no difference in pregnancy rates when heifers were inseminated with 2 or $20 \times 10^{\text {t }}$ total unsexed spermatozoa $(\mathrm{P}>0.05)$, but note that the low dose also contained catalase, Overall, pregnancy rates were higher $(42 \%)$ for spermatozoa frozen $8 \mathrm{~h}$ post-collection than for those frozen $13 \mathrm{~h}$ post-collection $(34 \%)(\mathrm{P}<0.03)$. There was no significant effect of stain concentration on pregnancy rates (36 vs. $41 \%$ for high and low stain, respectively: $P>0.1)$. There were no significant bull or herd effects $(P>0.1)$.

Table 5. Results of Trial 5. Effects of Hoechst 33342 concentration for staining spermatozoa and catalase on pregnancy rales.

\begin{tabular}{|c|c|c|c|c|c|c|}
\hline \multirow[b]{2}{*}{ Treatment/Spermatozoa } & \multicolumn{3}{|c|}{$T^{\text {sx }}$ Freeze } & \multicolumn{3}{|c|}{$2^{\text {"nd }}$ Freeze } \\
\hline & $\mathrm{N}$ & Na. preg & $\operatorname{LSM}(\%)^{*}$ & $\mathrm{~N}$ & No. preg & $\operatorname{LSM}(\%)^{*}$ \\
\hline $20 \times 10^{6}$ unsexed, without catalase & 240 & 142 & $59^{a}$ & & & \\
\hline $2 \times 10^{6}$ unsexed, with catalase (NSC) & 240 & 125 & $52^{\pi}$ & & & \\
\hline $\begin{array}{l}2 \times 10^{6} \text { sexed, high stain } \\
\text { without catalase }\end{array}$ & 138 & 58 & $39^{6}$ & 90 & 37 & 38 \\
\hline $\begin{array}{l}2 \times 10^{6} \text { sexed, high stain, } \\
\text { with catalase }\end{array}$ & 136 & 50 & $35^{c}$ & 96 & 32 & 30 \\
\hline $\begin{array}{l}2 \times 10^{6} \text { sexed, low stain, } \\
\text { without catalase }\end{array}$ & 87 & 46 & $47^{b, d}$ & 153 & 58 & 35 \\
\hline $\begin{array}{l}2 \times 10^{6} \text { sexed, low stain, } \\
\text { with catalase }\end{array}$ & 101 & 47 & $43^{b}$ & 129 & 52 & 37 \\
\hline
\end{tabular}

a.b.s.d Means within columns without common superscripts differ $(\mathrm{P}<0.05$ ).

* Overall, pregnancy rates for sexed, first batch inseminates were higher than second batch inseminales (42 vs $34 \%, \mathrm{P}<0.03)$.

\section{Trial 6 - Crossbred heifers in Wyoming}

Calving rates with sexed spermatozoa were approximately $75 \%$ of those for unsexed controls $\left(\mathrm{P}<0.05\right.$; Table 6). Freezing sorted spermatozoa at $20 \times 10^{6} / \mathrm{ml}$ was superior to $10 \times 10^{6} / \mathrm{ml}$, $225 / 422(53 \%)$ versus $196 / 414(47 \%)$ calving $(P<0.05$, 1 -tail $\chi 2$, data not presented in Table 6). The catalase treatment with sorted spermatozoa had no beneficial effect on calving rates. Furthermore, insemination of $2 \times 10^{6}$ unsexed control spermatozoa did not decrease calving rates significantly compared to $20 \times 10^{6}$ unsexed control spermatozoa $(P>0.05)$. Sexed inseminates resulted in excess birth of heifers $(88 \%)$ compared to that for unsexed controls $(51 \%)$. There were no significant bull effects $(P>0.1)$.

Table 6. Results of Trial 6. Effects of calalase on pregnancy rates of heifers inseminated with sexed frozen spermatozoa (pooled over spermatozoa concentrations in straws) or unsexed control spermatozoa.

\begin{tabular}{lccc}
\hline Treatment & $\mathrm{N}$ & $\begin{array}{c}\text { Number } \\
\text { calving to Al }\end{array}$ & $\begin{array}{c}\text { Least squares } \\
\text { means }(\%)\end{array}$ \\
\hline $20 \times 10^{6}$ unsexed (high control) & 209 & 144 & $70^{\circ}$ \\
$2 \times 10^{6}$ unsexed (low control) & 217 & 139 & $64^{\circ}$ \\
$2 \times 10^{6}$ sexed - without catalase & 421 & 206 & $49^{6}$ \\
$2 \times 10^{6}$ sexed - with catalase & 415 & 214 & $52^{6}$ \\
\hline
\end{tabular}

a, Least squares means without common superscripts differ $(P<0.05)$. 


\section{Discussion}

General characteristics of the field trials

The main objective of these experiments was to improve procedures for sexing spermatozoa with the important endpoint of pregnancy. Unfortunately, it is prohibitively expensive to obtain data on pregnancy rates in cattle under strictly controlled experimental conditions. We, therefore, worked with commercial producers. While there is considerable value in obtaining data under field conditions, there also are limitations: including varying levels of compliance with protocols; different levels of herd management; differing service sires and ages, weights, and breeds of animals; varying herd size et cetera. Some of these differences can be ameliorated by statistical procedures such as blocking; a particular problem is obtaining or accumulating sufficient numbers of animals to achieve reasonable statistical power for binomial responses such as percent pregnant.

We attempted to be sensitive to not reducing pregnancy rates greatly in these herds; we always included a standard Al control with normal doses of spermatozoa to established fertility with normal practices. Although this was not the best control for certain hypothesis testing, it was useful for several reasons, including showing that normal fertility was low in some herds, and having a portion of these heifers with normal pregnancy rates, even if our treatments resulted in low pregnancy rates. Ideally, we would have had a low spermatozoa dose unsexed control treatment in each experiment to compare with the low-dose sexed treatments. However, our main goals were to compare different approaches to sexing spermatozoa and maintaining their fertility, not to compare success rates of sexed spermatozoa treatments to nonsexed controls. Therefore, we usually did not use up the limited numbers of experimental animals for low-dose controls.

The pregnancy rates with doses of $2 \times 10^{6}$ sexed spermatozoa were lower than with $20 \times 10^{6}$ unsexed spermatozoa, ranging from 53.4 to $79.2 \%$ of those controls; average of $69.5 \%$ of controls (least squares mean comparisons) for the six trials. The pregnancy rates with sexed spermatozoa ranged from 31.5 to $50.5 \%$ in respective trials, averaged over all sexed treatments within each trial. Management appeared to account for most of these differences. Our university personnel did most of the estrus detection, semen handling, insemination and pregnancy diagnoses for Trials 1, 2, and 6. Pregnancy rates were clearly highest in these 3 trials, 46 to $50 \%$ with sexed spermatozoa, and were among the highest pregnancy rates with sexed spermatozoa as a percent of control 71 to $75 \%$. The highest pregnancy rate with sexed spermatozoa as a percent of controls was Trial 3, with $79 \%$; this trial was managed by a single person, although with two inseminators. One other telling statistic was from Trial 4, in which pregnancy rates with sexed spermatozoa as a percent of control were 60,64 , and $36 \%$ for high, medium, and low fertility herds (respective terciles). Thus use of low doses of sexed, frozen spermatozoa resulted in very poor fertility under suboptimal conditions and about 70 to $80 \%$ of controls with good management and strict compliance with protocols when inseminating heifers.

For Trials 3 through 5, we had no control over estrus detection, semen handling and insemination practices, pregnancy diagnoses or other management factors. Anecdotally, we know that standing estrus was not monitored in some cases, but rather any sign of estrus, such as mounting, mucus, rubbed off tail paint et cetera, was sufficient cause for insemination. Not only was overall fertility low in these trials but in most cases pregnancy rates with sexed spermatozoa were especially low.

In most trials, there were no effects due to bulls or inseminators. There are several plausible explanations for this. There were quality control standards in place for individual spermatozoa sorting batches; those not meeting standards were discarded so only good quality semen was used for all bulls. In cases where inseminators could be included in the statistical model, they 
were experienced, well-trained individuals. One other obvious constraint was that there were insufficient numbers of inseminations within most trials to compare bulls or inseminators with ideal statistical power. In most cases, differences would have had to exceed 12 to 15 percentage points for statistical significance.

\section{Treatment effects}

Here again, greater statistical power would have been desirable, which was compensated to some extent by studying effects in multiple trials. We studied two laser powers in four trials, the standard $150 \mathrm{~mW}$ compared with the lowest intensity that could be used and still resolve Xand $Y$-spermatozoa (50 to $130 \mathrm{~mW}$, depending on the particular sort run). Surprisingly, the higher laser power resulted in a significantly higher pregnancy rate than low laser power in Trials 1 (Table 1) and 4 (third versus fourth treatment listed in Table 4). A similar effect was noted by Guthrie et al. (2002). However, in two other field trials, the opposite effect was found, and if the data of the four trials are pooled in a meta-analysis, there is no significant effect of laser intensity (means of 43 and $38 \%$ for high and low laser power with over 400 inseminations per group). It appears that $150 \mathrm{~mW}$ of laser power as used was not any more detrimental than lower laser power. This is important because sorting can be done faster and more accurately at the higher laser power.

The concentration of Hoechst 33342 was studied in two trials, and no effect of concentration on fertility was observed. Previous studies (unpublished) with in vitro endpoints indicated that it would be desirable to keep the concentration of Hoechst 33342 on the low side. In vivo however there appears to be no major detriment to fertility at the higher stain concentration used.

The effect of supplementing spermatozoa-containing fluids with catalase in vitro and in two trials with substantive numbers of inseminates was studied. While catalase was beneficial when incubating spermatozoa in vitro for $2 \mathrm{~h}$, there was no effect on pregnancy rates of the treatments used. We postulated that hydrogen peroxide might be generated by the excessive manipulations that spermatozoa undergo in air in the process of sorting and that catalase might help. A meta-analysis combining treatments of Trials 5 and 6 indicates virtually identical fertility with and without catalase: $296 / 647(46 \%)$ and $301 / 649(46 \%)$, respectively. Catalase clearly is beneficial for bovine spermatozoa under some conditions (Shannon \& Curson 1972). Possibly the quality of the catalase we used was suboptimal.

The effects of spermatozoa concentration/dilution during cryopreservation were also studied. We observed a strong hint in Trial 4 that more concentrated spermatozoa may be desirable, and this was confirmed in Trial 6 . The published literature in this area is inconsistent for bull spermatozoa, although dilution is clearly harmful to spermatozoa of some species under some conditions (Maxwell \& Johnson 1999; Garner et al. 2001b). Use of $0.25 \mathrm{ml}$ straws instead of larger ones was chosen to minimize potential dilution effects, particularly since so few sexed spermatozoa are used per dose. However, dilution effects may not be sufficiently large to justify partial filling of $0.25 \mathrm{ml}$ straws to maintain a high spermatozoa concentration; thus conventional filling and sealing may be appropriate even though the spermatozoa concentration will be about $10 \times 10^{6} / \mathrm{ml}$ during freezing of $2 \times 10^{6}$ spermatozoa/dose.

\section{Other considerations}

The art and science of sorting spermatozoa by sex chromosomes continues to evolve. Particularly noteworthy is that sorting at 40 psi results in considerably higher spermatozoa quality than 
50 psi for most bulls and stallions (Suh et al. 2005). This also has been corroborated by fertility trials (Schenk et al., unpublished). The work reported in this paper was all done at 50 psi so maybe pregnancy rates would have been higher if sorting had been done with currently recommended procedures.

Another advance is using a much simpler laser that is less burdensome to operate and does not affect pregnancy rates adversely compared to a standard laser (Schenk et al. 2005). Still other advances, including that no egg yolk was needed in the glycerol fraction of extender for cryopreserving sexed spermatozoa (Schenk \& Crichton 2006), are making incremental improvements in the ease and speed of sorting while minimizing damage to spermatozoa.

\section{Conclusions}

The main findings from this research are that higher laser power, higher concentrations of Hoechst 33342 and lower concentrations of spermatozoa during cryopreservation were not detrimental, or only slightly detrimental, to the fertility of sexed, frozen bovine spermatozoa. Unfortunately, none of these findings is likely to have much effect on improving fertility of sexed spermatozoa. However, they will allow spermatozoa to be sexed more rapidly and efficiently, thus lowering the costs of sexing spermatozoa and making this technology available from a larger population of bulls.

\section{Acknowledgements}

We acknowledge the collaborators throughout the United States of America who allowed us to use their cattle including: Ben and Skylar Houston and staff of Aristocrat Angus, Platteville, CO; Ric Miller of Kiowa Creek Ranch, Elbert, CO (Trial 1), Robert Tointon of Tointon LLC, Walden, CO (Trial 2); staff at Cannon River Ranches, Highmore, SD (Trial 3); Roger Hanson and Lloyd Sorenson, D.V.M. of Accelerated Genetics, Baraboo, WI (Trials 3 and 4); Mel DeJarnette and Clif Marshall of Select Sires Inc., Plain City, OH (Trial 5); and Scott James of Padlock Ranches, Ranchester, WY (Trial 6). We greatly appreciate the livestock services of Pat Hemming, D.V.M. (Aristocrat Angus), Zella Brink and Rick Brandes (Colorado State University). The staff at XY, Inc.: Drs. Duane Garner and John Hasler assisted with experimental design; Lisa Massoudi, Kathy Mean, Mindy Meyers and Jodi Rasmussen provided technical assistance in sperm sorting and processing; Dr. TaeKwang Suh assisted with statistical analyses of data.

\section{References}

Ballachey BE, Hohenboken WD \& Evenson DP 1987 Heterogeneity of sperm nuclear chromatin struclure and its relationship to fertility of bulls. Biology of Reproduction 36 915-925.

Cran DG, Cochrane DJ, Johnson LA, Wei H, Lu KH \& Polge C 1994 Separation of X-and Y-chromosome bearing bovine sperm by flow cylometry for use in IVF. Theriogenology 41183 (abstr).

Darzynkiewicz Z, Tranganos F, Sharples T \& Melamed M 1975 Thermal denaturization of DNA in situ as studied by acridine orange staining and automated cytofluorometry. Experimental Cell Research 90 411-428.

Garner D, Schenk I \& Seidel G Jr 2001a Chromatin stability in sex-sorted sperm. In Proceedings of the VIlth International Congress of Andrology, Montreal. Andrology in the Twenty-first Century, Canada: Short Communications, pp 3-7. Eds B Bobaire, $H$ Chemes and CR Morales. Englewood, NI: Medimond.

Garner DL, Thomas CA, Gravance CG, Marshall CE, Dejarnette IM \& Allen CH 2001 b Seminal plasma addition attenuates the dilution effect in bovine sperm. Theriogenology 56 31-40.

Guthrie HD, Johnson LA, Garrett WM, Welch GR \& Dobrinsky FR 2002 Flow cytometric sperm sorting: effects of varying laser power on embryo development in swine. Molecular Reproduction and De- 
velopment $6187-92$,

Johnson LA, Flook JP \& Look MV 1987a Flow cytometry of $X$ and $Y$ chromosome-bearing sperm for DNA using an improved preparation method and staining with Hoechst 33342. Gamete Research 17 203212.

Johnson LA, Flook IP, Look MV \& Pinkel D 1987b Flow sorting of $\mathrm{X}$ and $\mathrm{Y}$ chromosome-bearing spermatozoa into two populations. Gamete Research 16 1-9.

Johnson LA \& Welch GR 1999 Sex preselection: highspeed flow cytometric sorting of $X$ and $Y$ sperm for maximum efficiency. Theriogenology 52 13231341.

Klinc P, Frese D, Osmers H, Sieg B, Struckmann C, Kosec M \& Rath D 2005 Successful insemination in heifers with sex-sorted bull spermatozoa using a new extender concept (Sexcess'). Reproduction îs Domestic Animals 40360 (abstr).

Libbus GL, Perreault SD, Johnson LA \& Pinkel D 1987 Incidence of chromosome aberrations in mammalian sperm stained with Hoechst 33342 and UVlaser irradiated during flow sorting. Mutation Research 182 265-274.

Maxwell WMC \& Johnson LA 1999 Physiology of spermalozoa at high dilution rales: The influence of seminal plasma. Theriogenology 52 1353-1362.

McNutt TL \& Johnson LA 1996 Flow cytometric sorting of sperm: Influence on fertilization and embryo/ fetal development in the rabbit. Molecular Reproduction and Development 43 261-267.

Muller W \& Gautier F 1975 Interactions of heteroaromatic compounds with nucleic acids. European foumal of Biochemistry 54 358-394.

Munné S 1994 Human sperm sex selection: Flow cytometry separation of $X$ and $Y$ spermatozoa could be detrimental for human embryos. Human Reproduction 9758 .

Parrilla I, Vázquez JM, Cuello C, Gil MA, Roca J, Di Berardino D \& Martinez EA 2004 Hoechst 33342 stain and u.v. laser exposure do not induce genotoxic effects in flow-sorted boar spermatozoa. Reproduction $128615-621$.

Schenk IL 1998 Bull semen collection procedures. In Proceedings of the $17^{\text {th }}$ NAAB Technical Conference on $A /$ and Reproduction, pp 48-58. Columbia, MO: National Association of Animal Breeders.
Schenk JL, Suh TK, Cran DG \& Seidel GE Jr 1999 Cryopreservation of flow-sorled bovine sperm. Theriogenology 52 1375-1391.

Schenk JL, Brink Z \& Suh TK 2005 Use of competitive fertilization to evaluate a simpler laser for flow cytometric sexing of bovine sperm. Reproduction. Fertility and Development 17306 (abstr).

Schenk J \& Crichton E 2006 Insemination of Holstein heifers with sexed sperm processed with or without egg yolk in the glycerol-containing freezing medium. Reproduction, Fertility and Development 18 282-283 (abstr).

Seidel GE Jr \& Garner DL 2002 Current status of sexing mammalian spermatozoa. Reproduction 124 $733-743$.

Seidel GE Jr \& Schenk IL 2002 Field trials with sexed, frozen bovine semen. In Proceedings of the 19th NAAB Technical Conference on $A l$ and Reproduction, pp 64-69. Columbia, MO: National Association of Animal Breeders.

Seidel GE Jr., Schenk IL, Herickhoff LA, Doyle SP, Brink Z, Green RD \& Cran DG 1999 Insemination of heifers with sexed sperm. Theriogenology 52 1407-1420.

Shin S 1986 The control of Mycoplasmas, Campylobacter fetus, Haemophilus somnus in frozen bovine semen. In Proceedings of the $11^{\text {th }}$ NAAB Technical Conference on $A I$ and Reproduction, pp 33-38. Columbia, MO: National Association of Animal Breeders.

Shannon P \& Curson B 1972 Toxic effect and action of dead sperm on diluted bovine semen. Journal of Dairy Science 55 614-620.

Suh TK, Schenk IL \& Seidel GE Ir. 2005 High pressure flow cytometric sorting damages sperm. Theriogenology 64 1035-1048.

Teng M, Usman N, Frederick CA \& Wang AHJ 1988 The molecular structure of the complex Hoechst 33258 and the DNA dodecamer d(CGCGAATTCGCG). Nucleic Acids Research 16 $2671-2690$.

Tubman LM, Brink Z, Suh TK \& Seidel GE Jr. 2004 Characteristics of calves produced with sperm sexed by flow cytometry/cell sorting. lournal of Animal science 82 1029-1036. 